\title{
USING STRATEGIC PERFORMANCE MEASUREMENT SYSTEMS \\ FOR STRATEGY FORMULATION: \\ DOES IT WORK IN DYNAMIC ENVIRONMENTS?
}

\author{
Josep Bisbe \\ ESADE Business School, Ramon Llull University \\ Avda. Pedralbes, 60-62 \\ 08034 Barcelona, Spain \\ Phone: +34 932806162; Fax: +34 932048105 \\ josep.bisbe@esade.edu
}

Ricardo Malagueño

University of Essex

Wivenhoe Park, Colchester

CO4 3SQ, United Kingdom

Phone: +44 (0) 1206873333

rmalag@essex.ac.uk 
To appear in Management Accounting Research 
To appear in Management Accounting Research

\title{
USING STRATEGIC PERFORMANCE MEASUREMENT SYSTEMS FOR STRATEGY FORMULATION: DOES IT WORK IN DYNAMIC ENVIRONMENTS?
}

\begin{abstract}
This paper examines how strategic performance measurement systems (SPMS) influence organisational performance through the shaping of the strategic agendas and strategic decision arrays that result from the processes of (re)formulation of intended strategies. Using a combination of archival and survey data collected from 267 medium and large Spanish companies, we find evidence supporting a positive association between SPMS and organisational performance which is mediated by the comprehensiveness of the strategic decision arrays. We find this mediation is negatively moderated by the level of environmental dynamism, so that the comprehensiveness of strategic decision arrays that result from strategy (re)formulation processes mediates the association between SPMS and organisational performance when environmental dynamism is low, but not when environmental dynamism is high.
\end{abstract}

Keywords: strategic performance measurement systems, balanced scorecard, strategy formulation, organisational performance, environmental dynamism

\section{Introduction}

Available data suggests that a large number of firms have significantly transformed their performance measurement and management systems during the last decade. A considerable component of this transformation has been the adoption of strategic performance measurement systems (SPMS) (Michele and Manzoni, 2010; Rigby, 2009). Underpinning these widespread processes of adoption, it has been claimed that SPMS have a beneficial impact on performance (Crabtree and DeBusk, 2008; Davis and Albright, 2004; de Geuser et al., 2009; Hoque and James, 2000) and that this impact is primarily achieved through the contribution of SPMS to the successful implementation (e.g. better communication, better 
execution, more effective follow-up) of intended strategies (Garengo et al., 2005; Kaplan and Norton, 2000, 2004; Murby and Gould, 2005).

These relatively well-established perceptions of SPMS have been challenged by recent research. An emerging stream of studies suggests that SPMS may effectively be used not only for ensuring the implementation of intended strategies but also for shaping the processes of their formulation (Bourne et al., 2000; Gimbert et al., 2010; Kaplan and Norton, 2008). However, despite the growing consensus in the literature about the positive association between SPMS and organisational performance, the empirical research that has examined the significance of the shaping of strategy (re)formulation processes as one possible explanation or channel for this association is still limited. While some research has examined the impact of SPMS on performance (Davis and Albright, 2004; de Geuser et al., 2009) and some studies have highlighted that firms in which SPMS are present engage in strategy formulation differently than those in which SPMS are not present (Gimbert et al., 2010), the connections between these two issues have not yet been addressed. Therefore, we detect a first gap regarding the extent to which the association between SPMS and organisational performance is at least in part accounted for by attributes of the strategy formulation processes. Hence, the thrust of our first research question is: in addition to the effects of SPMS on organisational performance that are generally attributed to strategy implementation, can the influence of SPMS on the processes of (re)formulation of intended strategies also help to explain how SPMS influence performance?

Recent literature also casts doubts on the ability of SPMS to actually support performance in dynamic environments. The extent to which the implications of SPMS depend on the dynamism of the environment has not been directly explored in previous empirical work, but prior theoretical arguments that have indirectly contributed to this debate point in conflicting 
directions. Some studies suggest that the adaptive capabilities that are needed in dynamic environments are increased when broader scope information is provided (Chenhall and Morris, 1986; Hoque, 2005). However, other studies have questioned whether SPMS can actually support performance in dynamic environments given the risks of over-commitment to specified intended strategic decisions in such contexts (Bukh and Malmi, 2005; Micheli and Manzoni, 2010; Norreklit, 2000). Taking into account the inconclusiveness of previous research, our second research question examines whether the association between SPMS and performance that is channelled through the strategy formulation processes depends on whether the company operates in a stable or dynamic environment. We aim to test whether the indirect effects of SPMS on performance acting through the attributes of strategy formulation processes are salient regardless of the level of environmental dynamism or are instead moderated by it.

To address these two research questions, we have counted on a combination of archival and survey data gathered from senior managers of 267 medium and large Spanish companies. For the survey data, this paper uses the same data set as Gimbert et al. (2010), but here the scope is substantially broadened to include two additional variables (namely environmental dynamism and organisational performance) obtained from publicly available archival data. Gimbert et al. (2010) was centred exclusively in the links between SPMS and attributes of the strategy (re)formulation processes. The expanded focus and incremental contribution of this paper result from extending the analysis to further investigate the implications of this association for organisational performance and whether the strength of these relationships depends on the dynamism of the environment.

The contribution of the paper is then two-fold. Firstly, we develop theoretical arguments and provide large-scale evidence that help explain some of the transmission mechanisms 
present in the association between SPMS and performance. We argue that the comprehensiveness of the strategic agendas and the strategic decision arrays that result from strategy (re)formulation processes (Dutton and Duncan, 1987; Nadkarni and Barr, 2008) help explain some of these transmission mechanisms and mediate such associations. In doing so, we extend the findings of Gimbert et al. (2010) to include the implications for organisational performance. We also extend previous empirical evidence that had linked SPMS and performance to emphasize the processes of (re)formulation of intended strategies as one of the channels through which that link is enacted.

The second contribution of the paper relates to the inclusion of environmental dynamism as a contingent variable. Limited streams of normative and theoretical literature have provided arguments both claiming and casting doubts on the suitability of SPMS in turbulent environments (Bukh and Malmi, 2005; Kaplan and Norton, 2000; Norreklit, 2000), but empirical quantitative evidence regarding this issue was missing. This study contributes to the literature by theoretically developing several of the reasons why the associations between SPMS and the comprehensiveness of strategic decision arrays and organisational performance may depend on the dynamism of the environment. We empirically test these associations on a large sample. Our findings provide evidence that environmental dynamism negatively moderates the association between SPMS and organisational performance that is mediated by the comprehensiveness of strategic decision arrays. We contribute to a better understanding of the implications of SPMS by highlighting that the positive consequences of the heightened comprehensiveness of strategic decision arrays that results from SPMS are more likely to be capitalised in the context of low environmental dynamism and that these positive consequences are more difficult to exploit in dynamic environments. 
The remainder of the paper is divided into five sections. Firstly, we provide the theoretical background of our study and introduce a series of testable hypotheses. This is followed by two sections that present the research method and results. These results are discussed in a fourth section. A final section offers conclusions and comments on limitations and opportunities for further research.

\section{Theoretical background and hypotheses formulation}

\section{SPMS, performance and strategy (re)formulation}

Performance measurement systems (PMS) are concise sets of metrics (which may be financial and/or non-financial, long and/or short term, internal and/or external, ex post and/or ex ante) that support the decision-making processes of an organisation by gathering, processing, and analysing quantified information about its performance, and presenting it in the form of a succinct overview (Gimbert et al., 2010; Henri, 2006; Neely et al., 1995). SPMS are a subset of PMS. Based on prior literature (Chenhall, 2005; Garengo et al., 2005; Gimbert et al., 2010; Hall, 2008, 2011), we define SPMS as those PMSs that present distinctive features such as: 1) the integration of long-term strategy and operational goals; 2) the provision of performance measures in the area of multiple perspectives; 3 ) the provision of a sequence of goals/ metrics/ targets/ action plans for each perspective; and 4) the presence of explicit causal relationships between goals and/or between performance measures. Instances of SPMS include tools such as Balanced Scorecards (BSC) (Kaplan and Norton, 1996, 2000, 2004); fully-fledged tableaux de bord (Bourguignon et al, 2004); and performance prisms (Neely et al., 2002). 
SPMS help translate strategy into objectives and measures that can be clearly communicated, thus facilitating the closure of the gap between the strategic vision of the firm and the management of its operating activities (de Geuser et al., 2009; Kaplan and Norton, 2000). This, in turn, enables the delegation of authority and the empowerment of people and sub-units while preserving alignment. Moreover, the explicit representation of the causeeffect relationships within the organisational model encourages learning and facilitates communication (Kaplan and Norton, 1996, 2000, 2004, 2006; Malina and Selto, 2001). As a result, decision-making processes should be more effective. Even though it has been pointed that the expected benefits of SPMS might be at risk if designed and used in a mechanistic and bureaucratic manner (Braam and Nijssen, 2004; Bukh and Malmi, 2005; Micheli and Manzoni, 2010), an increasing body of evidence is progressively converging to indicate that SPMS are positively associated with self-reported economic performance (Hoque and James, 2000), perceptual satisfaction by users (de Geuser et al., 2009; Ittner et al., 2003; Speckbacher et al., 2003), accounting performance (Davis and Albright, 2004), and stock market performance (Crabtree and DeBusk, 2008). ${ }^{1}$

Previous studies that have examined how SPMS influence performance have tended to focus on the role of SPMS in communicating the pre-defined intended strategies of a firm and facilitating their implementation (Atkinson, 2006; Braam and Nijssen, 2004; Kaplan and Norton, 2000, 2004; Murby and Gould, 2005). Consequently, little attention has yet been paid in empirical studies to the other roles that SPMS can play beyond mere strategy implementation. Nevertheless, an emerging stream of literature is suggesting that the range of

\footnotetext{
${ }^{1}$ Institutional and critical research has emphasized that the presence and availability of PMS may be attributed not only to the demands of technical imperatives or the expectation of increased economic effectiveness, but also to the conferment of social legitimacy, the compliance with external and institutional requirements, as well as to fad and fashion phenomena. As highlighted by these streams of research, presence and availability of a PMS do not preclude that such a system is used in a merely ritual manner or is ignored by organisational participants (Baxter and Chua, 2003).
} 
roles that SPMS may play in organisational life is far broader (Atkinson et al., 1997; Micheli and Manzoni, 2010; Tayler, 2010; Wiersma, 2009) and include supporting the bottom-up development of innovative initiatives and unanticipated emergent strategies (Bisbe and Otley, 2004; Henri, 2006; Simons, 1995; Tuomela, 2005; Widener, 2007); as well as assisting in the revision or (re)formulation of intended strategies (Bourne et al., 2000; Campbell et al., 2008, Gimbert et al., 2010; Kald and Nilsson, 2000; Kaplan and Norton, 2008). In this paper, we specifically focus on this latter role and investigate whether the plausible relationship that exists between SPMS and organisational performance is accounted for, at least in part, by variables related to the processes of (re)formulating intended strategies. The effects of SPMS on performance that are explained by other channels (represented by a dotted line in Fig.1) are outside the scope of this study.

A few generic normative claims and some anecdotal evidence have suggested that SPMS have the potential to effectively support the (re)formulation of intended strategies and that, through this channel, they may eventually enhance performance. Thus, Kaplan and Norton (2008) suggest that SPMS help managers discover whether assumptions underlying their intended strategy are flawed or obsolete, and also help managers rigorously re-examine and adapt their strategy, deciding whether incremental improvements will suffice or whether a new, transformational strategy is needed. Accordingly, some limited case-based evidence suggests that SPMS can be used to challenge strategic assumptions being made in strategic formulation. These actions increase the chance of identifying problems of mistaken assumptions, and therefore encourage strategic revision (Bourne et al, 2000). At a more instrumental level, statistical analyses of causal links between performance measures have been proposed as useful devices in identifying potential problems in a firm's intended strategy, and in testing hypothesised causal chains and adjusting or adapting such strategy 
accordingly (Campbell et al., 2008; Kaplan and Norton, 2008). While both these normative claims and this limited, mostly anecdotal, empirical evidence indicate that SPMS may play an active role in the processes of (re)formulating intended strategy, an in-depth theoretical development of the mechanisms explaining this association and large-scale evidence supporting it are still missing.

\section{H1. The mediating role of strategic decision arrays}

From a design lens on strategy, intended strategies are defined as the expression of a desired strategic direction deliberately formulated or planned by managers and based on an analysis of competitive dynamics and current capabilities (Johnson and Scholes, 2008). The (re)formulation of intended strategies is a purposefully designed, formalised, and analytical endeavour that includes three types of processes. Firstly, the development of initial integrated grand plans obtained through formal strategic planning. Secondly, the conscious and deliberate revision of initial plans based on perception by senior management of changes in competitive dynamics or current capabilities - as well as their perception of progress towards initially intended plans. The outcome of these revisions may take the form of an adjusted grand plan or a stream of explicit, intentional, and formally documented decisions taken by senior management over time, periodically or when circumstances warrant (Andersen, 2000; Johnson and Scholes, 2008; Sinha, 1990). Finally, it may also include the conversion of emerging strategies into new intended strategies. Senior management may capitalise on successful local experiments that were spontaneously developed across the organisation despite or in absence of intentions, and facilitate that these initially unanticipated ideas 
coalesce into new intended strategies that are now explicitly supported and formally reported and communicated by top management (Johnson and Scholes, 2008; Simons, 1995). ${ }^{2}$

In all these processes of (re)formulation of intended strategies, managers spread their limited attention across a restricted set or portfolio of strategic issues that constitute the strategic issue array or strategic agenda (Dermer, 1990; Dutton and Ashford, 1993; Nadkarni and Barr, 2008). The structure of a strategic agenda is defined by two attributes, i.e. issue array size (the number of issues considered at one time), and issue array variety (the diversity of issues considered at one time). Strategic agendas gain in comprehensiveness when the agenda structure is modified to increase issue array size or variety (Dutton, 1988; Dutton and Duncan, 1987).

Senior managers are more likely to recognise and actively respond to environmental changes that take place in issues that have gained the strategic agenda. Hence, strategic agendas shape the ability to engage in strategic responses and therefore shape the strategic decision array, i.e. the set or portfolio of strategic decisions that result from formal strategy (re)formulation processes (Dutton, 1988; Nadkarni and Barr, 2008). A strategy (re)formulation process with a small decision array size is one in which decision-makers only make a limited number of decisions related to strategic issues contained in the strategic agenda. On the other hand, a strategy (re)formulation process with a high decision array variety focuses attention and includes decisions on a broad, diverse range of strategic issues contained in the strategic agenda. Comprehensiveness refers to the degree to which organisations include a large number and variety of strategic decisions in the decision arrays that result from strategy (re)formulation processes. Strategic decision arrays gain in

\footnotetext{
${ }^{2}$ The role of SPMS in developing emergent strategies that are not, or have not yet become, intended strategies is outside of the scope of this paper.
} 
comprehensiveness when the strategic decision array structure is modified to increase the decision array size or the decision array variety.

We address our first generic question by specifically analysing whether the plausible relationship that exists between SPMS and organisational performance is accounted for, at least partially, by the comprehensiveness of the strategic decision arrays that result from the processes of (re)formulating intended strategies. This expectation can be decomposed into two sub-arguments: 1) that SPMS have a positive effect on the comprehensiveness of strategic decision arrays; and 2) that the comprehensiveness of strategic decision arrays has a positive effect on organisational performance.

The first of our sub-arguments has been developed and tested in Gimbert et al. (2010). Even though this sub-argument is not in itself an incremental contribution of this paper, we briefly recall it here since it is a key component of the mediation hypotheses that we will derive below. As developed in Gimbert et al. (2010), prior research based on cognitive and social psychology theories has shown that PMS (including SPMS) help frame the mental representations of managers because of their informational effects (e.g. choice and use of heuristics, extensive scanning, greater quantity, and wider diversity of acquired and processed information, selective attention focus) (Birnberg et al., 2007; Hall, 2011). Individual mental representations that senior managers develop about their organisations and environments are instrumental in defining the collective strategic agenda of the organisation (Dutton, 1988; Dutton and Jackson, 1987; Nadkarni and Barr, 2008). Taking into account the implications of SPMS for organisational processes (e.g. creation of a forum for communication, discourse elaboration and discussion; establishment of procedures for making collective decisions) (Hodgkinson et al., 2006; Langley, 1988; Nadkarni and Barr, 2008), it is reasonable to expect that SPMS foster awareness and shared understanding by top management of the multi- 
faceted complexities facing their firm. Therefore, SPMS make it possible that senior managers ground decisions on more varied information, and consequently, that senior managers include a larger and wider range of issues in the organisational strategic agenda, so increasing comprehensiveness. Since senior managers are more likely to make decisions on issues that are placed on the strategic agenda (Nadkarni and Barr, 2008), it is reasonable to expect that the increased comprehensiveness of the strategic agendas of firms where SPMS are present will be reflected in an increased comprehensiveness of the strategic decision array. Hence,

Hla: There is a positive association between SPMS and the comprehensiveness of the strategic decision arrays that result from strategy (re)formulation processes.

\section{INSERT FIGURE 1 HERE}

As far as the second sub-argument related to our first research question is concerned, we expect the comprehensiveness of the strategic decision arrays to have a positive effect on organisational performance. Despite a lack of full consensus, prior empirical evidence shows a preponderance of results supporting the idea that formal strategy formulation processes (at least modern versions that have an effective link between strategy formulation and strategy implementation, or ensure operating managers have enough room to take autonomous action) are consequential and have positive and significant effects on organisational performance (Andersen, 2000; Miller and Cardinal, 1994; Miller et al., 2004). 
If the strategic agendas and strategic decision arrays that are present in formal strategy formulation processes have been shaped by SPMS, then it is likely that more angles are captured of the emerging developments, trends, or events that have important implications for the achievement of the organisation's goals - and that a greater number of more varied decisions are activated as a response. Studies on the role of managerial cognition have shown that the comprehensiveness of the strategic agenda and the comprehensiveness of the decision array are critical vehicles through which strategy formulation affects the extent and direction of the strategic response to environmental changes (Dutton and Duncan, 1987; Miller et al., 2008). Given the multi-dimensional attention focus and the causal logics introduced by SPMS, it is reasonable to expect that in firms where SPMS are present, senior managers will be better equipped to understand what developments, trends, or events mean in terms of changes in environmental demands - and will consequently be better equipped to develop a proper strategic response (Nadkarni and Barr, 2008). This ability to successfully respond to changes in environmental demands should be eventually reflected in enhanced organisational performance (Chenhall and Langfield-Smith, 2003). Formally stated:

H1b: The comprehensiveness of the strategic decision arrays that result from strategy (re)formulation processes is positively associated with organisational performance.

Bringing together the expectation that there is a total positive effect of SPMS on organisational performance as derived from previous literature (Crabtree and DeBusk, 2008; Davis and Albright, 2004; de Geuser et al., 2009; Hoque and James, 2000) and the two subarguments deployed above, we therefore expect a pattern of partial mediation so that: 
To appear in Management Accounting Research

H1: The positive effect of SPMS on organisational performance is (partially) mediated by the comprehensiveness of the strategic decision arrays that result from strategy (re)formulation processes, such that SPMS have a positive effect on the comprehensiveness of the strategic decision arrays, which in turn has a positive effect on organisational performance.

\section{H2 - H4. The moderating role of environmental dynamism}

The broader contingency literature has consistently pointed to environmental dynamism as a key contextual factor that influences the appropriateness of specific management systems (Goll and Rasheed, 1997; Harrington et al., 2004; Hough and White, 2003; Priem et al., 1995; Rajagapolan et al., 1993; Simerly and Li, 2000). Environmental dynamism is a dimension of the environment that deals with whether the elements are changing unpredictably or follow stable patterns. It is defined as the rate of unexpected change or change that is hard to predict in a given environment (Dess and Beard, 1984; Sharfman and Dean, 1991). ${ }^{3}$

Previous literature provides indirect indications that environmental dynamism is also a potentially important variable for better understanding the implications of SPMS. Prior studies have concluded that broad scope information (Chenhall, 2007; Gordon and Narayanan, 1984) aids control by focusing information on the sources of perceived uncertainty (Chenhall and Morris, 1986) and also provides managers with a basis on which to manage the drivers of

\footnotetext{
${ }^{3}$ Environmental dynamism (used in the literature interchangeably with turbulence and instability) (Dess and Beard, 1984; Sharfman and Dean, 1991) is a construct that refers to changes in an industry and is generally measured through indicators that capture volatility of some 'objective' economic variables. A number of management accounting studies have used an alternative approach to capture characteristics related to the environment and have focused instead on a construct based on subjective perceptions, i.e. Perceived Environmental Uncertainty (PEU) (e.g. Gul and Chia, 1994; Hartmann, 2005; Hoque, 2005). See Sharfman and Dean (1991) for a discussion of the pros and cons of objective versus perceptual measures of environmental dimensions. See Simerly and Li (2000) for references regarding the association between environmental dynamism and PEU.
} 
desired outcomes under uncertain circumstances (Hoque, 2004, 2005). Moreover, companies competing in relatively stable markets face different information needs and risks of rigidity than firms operating in very dynamic environments. Consequently, as some recent theoretical (e.g. Bukh and Malmi, 2005; Micheli and Manzoni, 2010) and qualitative studies (e.g. Kolehmainen, 2010; Melnyk, 2010), have pointed out, firms in stable environments are likely to experience the influence of SPMS differently than firms operating in dynamic environments. Despite these indications, the empirical research that has investigated whether environmental dynamism affects the different channels by which SPMS influences organisational performance is still scarce (Bukh and Malmi, 2005; Micheli and Manzoni, 2010). To address this gap, we next consider arguments that suggest that environmental dynamism: a) moderates the relationship between SPMS and the comprehensiveness of the strategic decision arrays (H2); and b) moderates the relationship between the comprehensiveness of the strategic decision arrays and organisational performance $(\mathrm{H} 3)$.

Firstly, we expect that the strength of the association between SPMS and the comprehensiveness of array decisions (as predicted by H1a) will depend on the level of environmental dynamism. Firms operating in industries that exhibit great environmental dynamism need to monitor quickly changing conditions, assess the impact of conditions on the firm, and rapidly develop strategic responses (Milliken, 1987; Simerly and Li, 2000). Emergent strategies and informal mechanisms are likely to play an important role in helping firms cope with these highly volatile environments (Chenhall and Morris, 1986; Mintzberg et al., 1995), but we also expect SPMS to play a further role in this regard by activating intended strategies. In contexts of high environmental dynamism, the multi-faceted complexities faced by firms are increased. The informational effects of SPMS foster awareness by senior management of these increased multi-faceted complexities - as well as an awareness of the 
need to strategically respond. This awareness should facilitate the inclusion of issues in the strategic agenda (Dutton, 1988; Nadkarni and Barr, 2008), which in the case of highly dynamic environments should tend to include a larger and wider range of issues (Fredrickson and Mitchell, 1984; Goll and Rasheed, 1997; Hough and White, 2003). Since senior managers are more likely to make decisions on issues that are placed on the strategic agenda (Nadkarni and Barr, 2008), it is reasonable to expect that this increased comprehensiveness of the strategic agendas in dynamic environments will facilitate the ability to respond with more comprehensive strategic decision arrays in the processes of (re)formulating intended strategies (Gimbert et al., 2010). Hence,

H2: The positive relationship between the SPMS and the comprehensiveness of strategic decision arrays that result from strategy (re)formulation processes is stronger for firms facing high levels of environmental dynamism.

The strategic management literature has long considered environmental dynamism as a key determinant of the appropriateness of the attributes of strategy (re)formulation processes (Fredrickson and Mitchell, 1984; Goll and Rasheed, 1997; Harrington et al., 2004; Hough and White, 2003; Schwenk and Shrader, 1993). We expect environmental dynamism to play an important role in clarifying the relationship between organisational performance and the comprehensiveness of the decision arrays resulting from processes of (re)formulating intended strategy. A first line of reasoning suggests that more comprehensive strategic decision arrays should be especially appropriate in dynamic environments. If strategic decision arrays are limited in size and variety, the courses of action open to senior managers to respond to strategic changes are limited and point to a narrow scope of strategic issues. In 
contexts of low environmental dynamism, a large availability of alternative or complementary courses of actions and an array of decisions focused on a broad scope of strategic issues may be unnecessary for enhancing performance. Stability enables a concentration of the decision array on those issues that have proven relevant in the past. In contrast, the availability of many alternative or complementary courses of actions and an array of decisions focused on a broad scope of strategic issues should be helpful in dynamic environments to develop a proper strategic response that fosters the adaptive capabilities needed for competitive advantage and enhanced performance (Priem et al., 1995; Simerly and Li, 2000). Consequently, a more comprehensive strategic decision array should be instrumental in situations where it is more difficult to accurately assess the present and future state of the environment. The effects of a more comprehensive strategic decision array on performance should then be capitalised in dynamic environments.

However, a second contrasting perspective questions whether the more comprehensive strategic decision arrays that are associated with SPMS are actually beneficial in dynamic environments. Some studies have pointed out that as environmental dynamism increases, the ability of senior managers to accurately assess the present and future state of the environment decreases. This limits their ability to determine the direction and strength of the potential impact of the strategic decisions, and therefore the risk increases that decisions are flawed and do not eventually contribute to improved performance (Simerly and Li, 2000). A related stream of accounting literature has argued that in dynamic environments the commitment to any thoroughly detailed strategy mapping, or to a more comprehensive strategic decision array, may be riskier than facing a less comprehensive one, or even an unspecified strategy, since any chosen strategy may prove wrong. In highly dynamic environments, leaving strategy unspecified, decreasing the comprehensiveness of strategic decision arrays that result 
from processes of (re)formulating intended strategies and relying on an organisation's ability to cope with uncertainties may be more viable approaches than selecting a well-mapped strategy and translating it into a comprehensive strategic decision array and then asking an organisation to make a commitment (Bukh and Malmi, 2005). In a similar vein, Norreklit (2000) considers that because of the hierarchical, top-down approach adopted by many SPMS, the resulting strategic decision arrays tend to be static and rigid. If so, the strategic decision arrays resulting from SPMS will have difficulties in providing the flexibility needed to adapt intended strategies. The more comprehensive the strategic decision arrays, then the more likely that rigidities are built into the management systems, with the consequent risk that inertia and ossification offset the advantages of the availability of a large number and variety of predefined courses of action and strategic responses. This may not be a major problem for firms competing in relatively stable markets, but it becomes a serious concern for firms operating in highly dynamic environments (Micheli and Manzoni, 2010; Norreklit, 2000). This line of thought suggests that the positive consequences of the heightened comprehensiveness of strategic decision arrays that results from SPMS are more likely and easier to capitalise in the context of low environmental dynamism; whereas these consequences are less likely or more difficult to exploit in dynamic environments. We rely on the arguments provided by this last position to postulate that environmental dynamism should be expected to negatively moderate the relationship predicted by H1b. Hence:

H3: The positive relationship between the comprehensiveness of the strategic decision arrays that result from strategy (re)formulation processes and organisational performance is weaker for firms facing higher levels of environmental dynamism. 
Assuming that environmental dynamism positively moderates the association between SPMS and the comprehensiveness of strategic decision arrays, and that it negatively moderates the association between the comprehensiveness of strategic decision arrays and performance, then it is also likely that environmental dynamism will conditionally influence the strength of the indirect relationship between SPMS and performance - thereby demonstrating a pattern of moderated mediation. We expect that:

H4: Environmental dynamism moderates the positive and indirect effect of SPMS on organisational performance (through the comprehensiveness of strategic decision arrays). Specifically, the comprehensiveness of the strategic decision arrays that result from strategy (re)formulation processes mediates such indirect effect when environmental dynamism is low - but not when it is high.

\section{Research method}

\section{Sample selection and data collection}

This research relies on a combination of survey and archival data. The gathering of empirical data involved the administration of a questionnaire to a sample of CEOs in medium and large Spanish firms and the collection of archival data from the SABI database. ${ }^{4}$ For the purpose of sample selection, we defined medium and large firms as those with a minimum turnover of $€ 10$ million and a minimum of 50 employees. To control the potentially spurious effects of unanalysed variables, we circumscribed our database to unlisted firms from

\footnotetext{
${ }^{4}$ SABI (Iberian Balance Sheet Analysis System) is published by Informa D\&B and contains general information and annual accounts of Spanish and Portuguese firms.
} 
industrial and service industries in Catalonia (Spain). Our use of the SABI 2003 database yielded 2,021 firms meeting the screening criteria.

Questionnaires were distributed and returned by post. Following Dillman's (2002) guidelines, several procedures were employed to increase the likelihood of a high response rate and the likelihood of CEOs receiving and personally replying to the questionnaire. A first round of questionnaires was sent out in June 2005 and 251 complete questionnaires were returned. A second round of follow-up questionnaires was sent out in September 2005 to nonrespondents. After the two rounds, a total 357 of questionnaires had been returned. Of these, 349 were complete, representing a response rate of $17.27 \%$. This compares well with the response rate in similar studies (Van der Stede et al., 2005). T-tests supported the absence of differences between early and late respondents and of any obvious non-response bias. Harman's one-factor test indicated the absence of common method effects in our survey data. After combining the self-reported survey data with archival data obtained from the SABI 2008 database on performance for the years 2005 to 2007, and excluding cases with missing values, we obtained a sample of 294 firms. Since the questionnaire required respondents to recall events from the previous three years, it was considered for the sake of temporal consistency that fully competent respondents should be senior managers who had been members of top management teams for at least this period. Consequently, we excluded 27 cases where the respondents reported that they did not fulfil this condition. The resulting useable sample for statistical testing was 267 firms. Appendix A reports the classification of these firms by industry. 


\section{Variable measurement}

SPMS was measured with the instrument described in Gimbert et al. (2010). Drawing on relevant literature that examines SPMS (Chenhall, 2005; Garengo et al., 2005; Hall, 2008; Speckbacher et al., 2003) this instrument considers four constitutive theoretical properties or dimensions of an SPMS: the integration of long-term strategy and operational goals; the presence of explicit causal relationships between goals and/or between performance measures; the presence of a sequence goals/metrics/targets/action plans; and the provision of performance measures in the area of multiple perspectives. A series of eight items asked respondents about the extent to which these four characteristics were provided by performance measurement systems in their firms. The first two of the constitutive dimensions were measured using summated scales from multiple reflective items with 5-point Likert scales adapted from Chenhall, 2005. Items I to III in Table 1 Panel B are related to the first of these dimensions, while items IV to VI are related to the second. After testing for unidimensionality, we obtained a Cronbach's $\alpha>0.9$ for these two constitutive dimensions, supporting high reliability (see Table 1). The third constitutive dimension was measured by the sum of four dummy items in which respondents evaluated if the performance measurement system in place explicitly contained: a) goals; b) metrics; c) targets and/or d) action plans (summarized in Item VII). The fourth constitutive dimension was measured by the number of perspectives that the firm reported capturing (out of an open list that enumerated examples of perspectives, based on Kaplan and Norton, 1996). The resulting score of each of the four dimensions was converted into a common scale (i.e. a coefficient equal to the least common multiple of the maximum values of the four theoretical ranges divided by the maximum value of the theoretical range of a given dimension was applied to 
To appear in Management Accounting Research

the score of that dimension). The practice-based construct SPMS was formatively operationalised as the average of the converted scores of the four equally weighted constitutive dimensions. Descriptive statistics are reported in Table $1 .^{5}$

To capture different angles of the comprehensiveness of the strategic decision arrays that result from strategy (re)formulation processes, we measured both strategic decision array variety $(A V R)$ and strategic decision array size (ASZ). Following Gimbert et al. (2010), the two variables were captured by an instrument where respondents indicated the number of occasions in which intended strategic decisions regarding a series of strategic issues were made in formal strategic (re)formulation processes. An open list that enumerated instances of potential strategic issues derived from Prahalad and Doz (1987), Sinha (1990) and Dean and Sharfman (1996) (e.g. opening of foreign markets, outsourcing, know-how development) was included in the instrument. This instrument asked respondents about 22 items, each of which referred to the number of occasions when strategic decisions regarding one of these issues were made over the last three years. The number of decisions was measured as the sum of the scores of these items, i.e. the sum of the reported occasions in which decisions regarding any strategic issue were made as a result of the formal strategic formulation processes. The variety of decisions was measured as the number of strategic issues that were object of strategic decisions at least once in the formal strategic formulation processes over the last three years. Comprehensiveness of strategic decision arrays was operationalised by separately capturing these two differing yet related angles.

\footnotetext{
${ }^{5}$ In line with most previous studies (e.g. Chenhall, 2005; Hall, 2008, 2011), in this paper we follow a continuous approach to measure SPMS. Some studies (e.g. Gimbert et al., 2010) have opted for a configurational approach by which SPMS is dichotomized in terms of presence versus non-presence of SPMS. The replication of all tests included in this paper using a configurational approach to measure SPMS produced results that are fully consistent with the results reported here.
} 
Environmental dynamism was defined as the rate of unexpected change or change that is hard to predict in a given environment (Dess and Beard, 1984; Harrington et al., 2004 Priem et al., 1995; Sharfman and Dean, 1991; Simerly and Li, 2000). The environmental dynamism faced by a firm was considered to be the market dynamism (Sharfman and Dean, 1991; Simerly and Li, 2000) of the industry the firm belongs to (according to the Clasificación Nacional de Actividades Económicas CNAE 2009 coding scheme). This approach, based on archival data, has consistently been applied in previous research (e.g. Dess and Beard, 1984; Harrington et al., 2004; Simerly and Li, 2000). In line with these studies, dynamism was operationalised as a standardised measure of the volatility of industry sales and the number of employees over the 2002-2004 period (obtained from SABI). We followed the procedure used, among others, by Sharfman and Dean (1991), Goll and Rasheed (1997) and Harrington et al. (2004), and specifically measured environmental dynamism (DYN) of an industry by computing the standard error of the regression of industry sales for the period 2002-2004 on a variable representing the time period. To obtain a standardised indicator, the standard error of the resulting regression slope was divided by the industry sales average. An analogous procedure was used for the number of employees, and the overall measurement of environmental dynamism was operationalised as the sum of the two standardised indicators of dynamism for sales and number of employees.

In accordance with usual procedures in empirical research when dealing with unlisted companies, organisational performance refers to operational efficiency and was measured through two financial accounting ratios: return on assets $(R O A)$ and return on sales $(R O S)$ (e.g. Goll and Rasheed, 1997; Simerly and Li, 2000; Van der Stede, 2000; Widener, 2006). Using the SABI 2008 database, ROA and ROS data was collected for each firm in the sample for the three years between 2005 and 2007 (three years lagged in relation to the rest of the 
variables of interest in this study). To control for industry effects on financial performance, we computed the dominant two-digit CNAE industry average for ROA and ROS for the three years between 2005 and 2007. We measured a firm's performance on ROA (ROS) as the difference between the firm's average 2005-2007 ROA (ROS) and the respective industry average 2005-2007 ROA (ROS). Finally, we included size (SIZE) and headquarters vs. subsidiary $(H Q)$ as control variables. The former was measured as the logarithm of the number of employees for each company. The latter is a dummy variable that equals 1 if the observation represents headquarters and 0 otherwise.

Table 1 reports the descriptive statistics of these variables. In addition, the table presents a comparison of their scores between sub-samples split by firm size (i.e. medium vs. large firms), company structure (headquarters vs. subsidiary), and by presence of SPMS. No significant differences were found for any of the variables between the sub-samples split on the basis of firm size and structure. In contrast, a battery of t-tests suggested that strategic decision array variety, strategic decision array size, and organisational performance (ROA and ROS) were significantly higher in firms in which SPMS were present than in firms in which SPMS were not present. However, we did not find evidence of significant differences in environmental dynamism between firms in which SPMS were present and firms in which they were not. The Pearson correlation coefficients for zero-order relationships among the variables are displayed in Table 2.

INSERT TABLE 1 AND TABLE 2 


\section{Results}

We tested our hypotheses in two steps. Firstly, we examined a simple mediation model to test the mediating role of strategic decision arrays in the relationship between SPMS and organisational performance (H1). Secondly, we integrated environmental dynamism as a proposed moderator variable into the mediation model to test the significance of the moderation on each of the two mediated paths $(\mathrm{H} 2$ and $\mathrm{H} 3)$ as well as to test the moderated mediation hypothesis (H4). For each of the two models, we proposed two variations that refer to the two measures of organisational performance (ROA and ROS). These variations were further duplicated in order to test each variation for each of the two angles of comprehensiveness of strategic decision arrays (i.e. array size and array variety).

\section{Hypothesis H1}

We performed the test of $\mathrm{H} 1$ and its sub-hypotheses using the SPSS macro for mediation provided by Preacher and Hayes, 2004, which incorporates a causal steps and a bootstrapping procedure. The causal steps procedure tests the significance of three paths: the total effect of an antecedent variable on a criterion variable; the effects of the antecedent on the mediator; and the effect of the mediator on the criterion. If all three paths are found to be significant, then the criteria for partial mediation are considered to be fulfilled (Baron and Kenny, 1986; Mathieu and Taylor, 2006; Preacher and Hayes, 2004). The Preacher and Hayes procedure further bases the mediation analysis on nonparametric bootstrapping procedures to overcome potential shortcomings related to low statistical power and to provide a formal direct test of 
the mediation hypotheses (Edwards and Lambert, 2007; Hayes, 2009; MacKinnon et al., 2002, 2007).

Panel A in Table 3 displays the results of the causal steps procedure. It shows that SPMS have a positive effect on the strategic decision array variety $(\mathrm{p}<0.01)$, which in turn, has a positive effect on organisational performance measured through $\operatorname{ROS}(\mathrm{p}<0.05)$. Analogously, results shows that SPMS have a positive effect on the strategic decision array size $(\mathrm{p}<0.01)$, which in turn has a positive effect on $\operatorname{ROS}(\mathrm{p}<0.01)$ as well as on ROA $(\mathrm{p}<$ 0.05). Overall, these results suggest that, as predicted by H1a, SPMS are positively associated with the comprehensiveness of strategic decision arrays and that, as predicted by H1b, the comprehensiveness of strategic decision arrays is positively associated with organisational performance. Together, these findings fulfil the conditions (Preacher et al., 2007) to consider that the comprehensiveness of strategic decision arrays mediate the relationship between SPMS and organisational performance. More specifically, and since a total effect of SPMS on performance is initially present $(\beta=0.185 ; p<0.01$ for ROS; $\beta=0.130 ; p<0.05$ for ROA), the results support a pattern of partial mediation (Mathieu and Taylor, 2006).

As part of the Preacher and Hayes (2004) procedure, we further directly tested the presence of mediation by using 5000 bootstrap samples of the indirect effect (i.e. the product of the two mediated paths) and estimating the percentile-based $95 \%$ confidence intervals. When strategic decision array variety was used as a mediator, the indirect effect was found to be significant for ROS (as reported in Table 3 Panel B, p < 0.05). The bootstrapped 95\% confidence intervals around such indirect effects did not contain zero (Panel C in Table 3). When strategic decision array size was used instead as a mediator, the indirect effect was found to be significant for ROS $(\mathrm{p}<0.05)$ as well as for ROA $(\mathrm{p}<0.05)$. The bootstrapped 95\% confidence intervals around such indirect effects did not contain zero values either. 
Hence, the results of the Preacher and Hayes procedure lend support in favour of the mediation hypothesis stated by $\mathrm{H} 1$.

The indirect effects representing mediation are statistically significant but have modest practical significance, as shown by both the product of the coefficients of the mediated paths obtained in the causal steps procedure and the average of the indirect effects obtained from the bootstrapped results (Table 3). As discussed below, once environmental dynamism is introduced as a moderator in the mediation, the results reveal meaningful patterns regarding the practical significance of the mediation at different levels of environmental dynamism.

\section{Hypotheses $\mathrm{H} 2$ to $\mathrm{H} 4$}

We tested moderation on each of the two moderation paths ( $\mathrm{H} 2$ and $\mathrm{H} 3)$ as well as the moderated mediation hypothesis (H4) using the approach and SPSS macro provided by Preacher et al. (2007). This procedure tests moderated mediation by estimating the sampling distribution of the conditional indirect effect non-parametrically through bootstrapping and then uses the information from the bootstrap sampling distribution to generate confidence intervals for the conditional indirect effects. The significance of the conditional indirect effect is then tested at different levels of the moderator variable.

Panel A in Table 4 displays the results of the moderated multiple regressions with comprehensiveness of the strategic decision arrays as the dependent variable (measured by both array variety and array size). It shows that, contrary to what was expected by $\mathrm{H} 2$, the effect of SPMS on the comprehensiveness of the strategic decision array is not conditional on 
environmental dynamism. The interaction coefficients SPMS x DYN are significant neither for array variety nor for array size (both $\mathrm{p}>0.10)$. Hence, H2 is not supported. ${ }^{6}$

\section{INSERT TABLE 4 HERE}

Panel B in Table 4 displays the results of the moderated multiple regressions with comprehensiveness of the strategic decision arrays as a mediator, environmental dynamism as a moderator, and organisational performance as the dependent variable. The results obtained suggest that the interaction terms between the attributes of strategic decision arrays and environmental dynamism are negative for all variations of the model, even though negative interaction terms were not significant when ROA was taken as a measure of performance. However, using ROS as a measure of performance, we found negative and significant coefficients for the interactions between environmental dynamism and the comprehensiveness of strategic decision arrays (when measured by array variety, AVR x DYN, p $<0.01$, as well as when measured by array size, ASZ $x$ DYN, $p<0.01)$. This suggests that the effect of the comprehensiveness of the strategic decision array on organisational performance (at least when measured by ROS) becomes weaker when environmental dynamism increases. These results lend support in favour of $\mathrm{H} 3$.

The results described above examined the possible moderating effect of environmental dynamism on each of the two paths of the mediated relationship, but do not directly assess

\footnotetext{
6 In addition to the tests for $\mathrm{H} 2$ reported in Table 4, we further tested potential moderation effects of environmental dynamism on the relationship of each of the four constitutive dimensions of SPMS and the comprehensiveness of strategic decision arrays. The results of moderated regression analysis (not reported in this paper) did not reveal any significant moderation effects for any of the four tested models.
} 
conditional indirect effects and are therefore insufficient to test the moderated mediation predicted in H4 (Preacher et al., 2007). To do so, we applied the Preacher et al. (2007) procedure. We computed estimates for the indirect effect of SPMS through the comprehensiveness of strategic decision arrays on performance at different values of environmental dynamism. For each of these models, we used 5000 bootstrap samples of the indirect effect (i.e. the product of the two mediated paths) and we estimated percentile-based $95 \%$ confidence intervals for the indirect effect.

In Panel C in Table 4, we report the conditional indirect effect of SPMS on performance (through the comprehensiveness of strategic decision arrays) at three values of the moderator variable - namely the mean of environmental dynamism; one standard deviation above the mean; and one standard deviation below the mean. The reported results reveal that the indirect effects through array variety are positive and statistically significant for ROS at values of environmental dynamism - 1 standard deviation below the mean $(\mathrm{p}<0.05)$ and at values equal to the mean $(\mathrm{p}<0.10)$. The same analysis was used for array size as a measure of the comprehensiveness of strategic decision arrays. The reported results reveal that the predicted indirect effects are statistically significant at values of environmental dynamism -1 standard deviations below the mean as well as at values equal to the mean (in both cases, $\mathrm{p}<0.10$ for ROA and $\mathrm{p}<0.05$ for ROS). In contrast, for both array variety and array size, no indirect effect is significant at values of environmental dynamism +1 standard deviation above the average. Finally, Panel D in Table 4 illustrates the significance of the indirect effects at different levels of environmental dynamism. The range of values displayed in Panel D represents an abbreviated version of the output provided by the macro. The results confirm that the indirect effects of SPMS on performance mediated by the comprehensiveness of strategic decision arrays are statistically significant in low to medium levels of environmental 
dynamism, but they are not significant at high levels of environmental dynamism. Hence, these findings lend support to $\mathrm{H} 4$.

Table 4 is also useful for observing the practical significance of the indirect effects in each variation of the mediation model at different levels of environmental dynamism. The average of the indirect effects obtained from the bootstrapped results (which would equal the product of the coefficients of the mediated paths obtained through causal steps procedure) shows a pattern that indicates considerable practical significance for low levels of environmental dynamism (for example, at environmental dynamism $=0.005$, indirect effect $=0.119$ for array size and ROS). However, the practical significance of the mediation is negligible in dynamic environments (for example, at environmental dynamism $=0.096$, indirect effect $=-0.007$ for array size and ROS). Overall, the results presented in Table 4 support that the relationship between SPMS and organisational performance is mediated by the comprehensiveness of the strategic decision array when environmental dynamism is low, but not when environmental dynamism is high.

\section{Discussion}

The first research question of this study investigates the mediating role of the strategic decision arrays that result from (re)formulation processes in the association between SPMS and organisational performance. In order to do so, we initially relied on the arguments developed by Gimbert et al. (2010), who claim that the causal, multi-perspective approach of SPMS and their informational effects help frame the mental representations of senior managers (Birnberg et al., 2007; Hall, 2011), which in turn shape and increase the comprehensiveness of strategic decision arrays at the organisational level (Dutton and 
Jackson, 1987; Dutton, 1998; Nadkarni and Barr, 2008). In this paper, we have broadened the focus to further examine the implications of the relationship between SPMS and strategy formulation on performance. In accordance with our expectation, and in line with the arguments that state that strategic agendas and strategic decision arrays are critical vehicles through which strategy formulation affects the extent and direction of strategic responses to environmental changes (Dutton and Duncan, 1987; Miller et al., 2008, Nadkarni and Barr, 2008), our findings indicate that the comprehensiveness of strategic decision arrays is positively associated with organisational performance. These results when combined support our expectation that the positive effect of SPMS on organisational performance is in fact mediated by the comprehensiveness of strategic decision arrays. Our study highlights that although SPMS most likely have a direct effect on organisational performance that comes from other roles or other sources, the association between SPMS and performance is partially accounted for by the shaping of the strategic agendas and strategic decision arrays that result from the processes of (re)formulating intended strategy.

Our second research question focused on the potential moderating roles of environmental dynamism. We have made a distinction between potential moderating effects of environmental dynamism on the relationship between SPMS and comprehensiveness of strategic decision arrays on the one hand, and the potential moderating effects on the relationship between comprehensiveness of the strategic decision arrays and organisational performance on the other hand. As far as the first moderating effect is concerned, and contrary to our initial expectation, we did not find evidence that the positive association between SPMS and comprehensive strategic decision arrays is particularly strong in highly dynamic environments. Our results indicate that SPMS tend to increase the comprehensiveness of strategic decision arrays that result from processes of (re)formulation of intended strategies, 
regardless of the level of environmental dynamism. This finding suggests that SPMS mobilise on their own the decision-making processes in favour of the introduction of more and more diverse issues in the strategic agenda and, consequently, of increasingly varied strategic decisions in the strategic decision arrays. The strength of this mobilisation and the momentum that is created appears not to be associated with environmental dynamism, but to rely primarily on the modified mental representations and cognitive structures induced by causal, multi-perspective SPMS (Birnberg et al., 2007; Markman and Gentner, 2001; Nadkarni and Barr, 2008). It is plausible that, by enhancing the awareness of senior managers of the multifaceted complexities faced by the firm and by providing them with a shared mental map of the causal chains within the firm, SPMS by themselves induce senior managers to increase the comprehensiveness of the strategic decision arrays, independently of the level of environmental dynamism. Our results provide further indication of the independence between environmental dynamism and SPMS as evidenced by the lack of correlation between the two.

In contrast, and as initially posited as part of our second research question, we did find evidence for a moderating role of environmental dynamism in the relationship between comprehensiveness of strategic decision arrays and performance. Our results are consistent with the expectation that the positive relationship between the comprehensiveness of the strategic decision arrays and performance is weaker for firms facing higher levels of environmental dynamism than for firms in stable environments. This is in line with the positions that claim that dynamic environments increase the risks of committing to very comprehensive strategic decision arrays - given that the higher the comprehensiveness of the decision arrays, the more likely that rigidities, inertia, and ossification are built into the management systems, eventually hindering organisational performance (Bukh and Malmi, 2005; Micheli and Manzoni, 2010; Norrklit, 2000). 
The finding that environmental dynamism negatively moderates the relationship between comprehensiveness of strategic decision arrays and performance also has implications for the mediated relationship between SPMS and performance. In fact, our results support a pattern of moderated mediation by which environmental dynamism moderates the positive and indirect effect of SPMS on organisational performance (acting through the comprehensiveness of strategic decision arrays). In stable environments, SPMS are positively associated with the comprehensiveness of the strategic decision arrays and, in turn, the association between comprehensiveness of strategic decision arrays and performance is also significantly positive. Hence, we have found that the comprehensiveness of strategic decision arrays mediates the effect of SPMS on organisational performance when environmental dynamism is low. At these low levels of environmental dynamism, such mediation has both statistical and practical significance. This is not the case in dynamic environments, where even if SPMS are still positively associated with the comprehensiveness of strategic decision arrays, the benefits of the comprehensiveness of strategic decision arrays weaken. The evidence we have found indicates that in such dynamic environments, firms are less likely to exploit this higher comprehensiveness in favour of enhanced performance, and consequently, the comprehensiveness of strategic decision arrays does not mediate the relationship between SPMS and performance.

\section{Conclusion}

This study contributes to a better understanding of the extent to which SPMS influence organisational performance through their contribution to the processes of (re)formulating intended strategies. It provides both theoretical developments and large-scale empirical 
evidence that, despite being primarily conceived to facilitate strategy implementation, SPMS influence performance not only through such implementation as generally discussed in previous empirical research, but also through the shaping of strategic agendas and the strategic decision arrays that result from the (re)formulation of intended strategies. This has practical implications since managers of organisations that already have SPMS in place and are aware of the role of SPMS in the improved implementation of strategies should also be aware of and exploit the positive implications of SPMS for strategy (re)formulation purposes on performance. In turn, managers of organisations that do not have SPMS in place should include the potential implications of SPMS on performance acting through strategy (re)formulation when pondering the advantages and drawbacks of an eventual adoption of SPMS.

Furthermore, this paper also investigates whether the strength of the influence of SPMS on performance acting through strategy (re)formulation depends on the level of environmental dynamism. We have concluded that environmental dynamism is a critical factor that significantly influences the strength of the mediated effect of SPMS on performance, and that that this positive mediated effect is salient in stable environments - but diminishes as environmental dynamism grows. This moderated mediation pattern also has practical implications for managers since it highlights that companies in stable environments are more likely to capitalise the beneficial effects of SPMS operating through strategy (re)formulation; whereas companies in very dynamic environments will find it harder to exploit such effects.

Some limitations must be noted so that they can be addressed in subsequent research. Firstly, the sample of our study was selected from medium and large industrial and service firms in a given geographical area. Generalising the results to organisations in other areas should be done with caution. Secondly, future studies in this area should also develop more 
refined measurement instruments. We opted for using a combination of survey and publicly available archival data in order to avoid single source and common method biases. However, potential concerns regarding some of the self-reported measures still exist, in particular regarding the accuracy of recall. We encourage future research to further refine such measurement instruments to address these concerns. Finally, since background theory was considerably developed, but little quantitative evidence was available, we opted for a largesample, cross-sectional study in order to contribute to advancing current knowledge in this area. As happens with any methodology, we acknowledge limitations in our study that are inherent to the selected research design. We used lagged archival measures of performance to at least partially mitigate potential concerns about reversed causality and endogeneity, but we accept that these concerns cannot be completely ruled out and that strict causality cannot be claimed. To better understand the dynamics and qualitative aspects underlying the relationships found in this study, we encourage further longitudinal case studies to extend and complement our findings. 
To appear in Management Accounting Research

Appendix A: Classification of firms in the sample by industry

\begin{tabular}{|l|r|r|}
\hline Industry classification (CNAE) $\dagger$ & Frequency & $\%$ \\
\hline Food (CNAE 10) & 12 & $4.5 \%$ \\
\hline Textiles and clothing manufacturing $(13,14)$ & 6 & $2.2 \%$ \\
\hline Wood and paper $(16,17)$ & 11 & $4.1 \%$ \\
\hline Printing and reproduction of recorded media $(18,58)$ & 7 & $2.6 \%$ \\
\hline Chemicals (20) & 21 & $7.9 \%$ \\
\hline Pharmaceuticals (21) & 12 & $4.5 \%$ \\
\hline Plastics (22) & 7 & $2.6 \%$ \\
\hline Other non-metallic mineral products $(23)$ & 7 & $2.6 \%$ \\
\hline Metallurgy and metal products $(24,25)$ & 12 & $4.5 \%$ \\
\hline Computers, electronic, and optical components $(26,27,31,32)$ & 9 & $3.4 \%$ \\
\hline Machines, equipment, motor vehicles $(28,29)$ & 21 & $7.9 \%$ \\
\hline Building construction $(41,42,43)$ & 26 & $9.7 \%$ \\
\hline Sale and repair of motor vehicles $(45)$ & 12 & $4.5 \%$ \\
\hline Wholesale trade and commission trade $(46)$ & 61 & $22.8 \%$ \\
\hline Retail $(47)$ & 9 & $3.4 \%$ \\
\hline Transport related activities $(49,52)$ & 10 & $3.7 \%$ \\
\hline Insurance, financial, legal, accounting services $(62,66,69,71,72,77,79)$ & 18 & $6.7 \%$ \\
\hline Other services $(55,56,80)$ & 6 & $2.2 \%$ \\
\hline Total & 267 & $100.0 \%$ \\
\hline
\end{tabular}

(Clasificación Nacional de Actividades Económicas, Spanish Standard Industrial Classification) 
To appear in Management Accounting Research

\section{References}

Andersen, T.J., 2000. Strategic planning, autonomous actions and corporate performance. Long Range Planning 33(2), 184-200.

Atkinson, H., 2006. Strategy implementation: a role for the balanced scorecard? Management Decision 44(10), 1441-1460.

Baron, R. M., Kenny, D. A., 1986. The moderator-mediator variable distinction in social psychological research: Conceptual, strategic, and statistical considerations. Journal of Personality and Social Psychology 51, 1173-1182.

Baxter, J., Chua, W.F. 2003. Alternative management accounting research- whence and whither. Accounting, Organizations and Society 28 (2-3), 97-126.

Birnberg, J.G., Luft, J., Shields, M.D., 2007. Psychology theory in management accounting research. In: Chapman, C.S., Hopwood, A.G., Shields, M.D. (Eds.), Handbook of Management Accounting Research. Elsevier: Oxford, pp. 113-136.

Bisbe, J., Otley, D. 2004. The effects of the interactive use of management control systems on product innovation. Accounting, Organizations and Society 29(8), 709-737.

Bourguignon, A., Malleret, V., Nørreklit, H., 2004. The American balanced scorecard versus the French tableau de bord: the ideological dimension. Management Accounting Research 15(2), 107-134.

Bourne, M., Mills, J., Wilcox, M., Neely, A., Platts, K. 2000. Designing, implementing and updating performance measurement systems. International Journal of Operations \& Production Management 20(7), 754-771.

Braam, G.J.M., Nijssen, E.J. 2004. Performance Effects of Using the Balanced Scorecard: A Note on the Dutch Experience. Long Range Planning 37 (4), 335-349.

Bukh, P.N., Malmi, T. 2005. Re-examining the cause-and-effect principle of the balanced scorecard. In: Mourtisen J., Jönsson, S. (Eds.), Northern Lights in Accounting., Liber: Stockholm.

Campbell, D., Datar, S., Kulp, S.C., Narayanan, V.G., 2008. Using the Balanced Scorecard as a control system for monitoring and revising corporate strategy. Working Paper Harvard Business School, available at SSRN: http/ssrn.com/abstract=328880.

Chenhall, R.H., 2005. Integrative strategic performance measurement systems, strategic alignment of manufacturing, learning and strategic outcomes: an exploratory study. Accounting, Organizations and Society 20, 395-422.

Chenhall, R.H., 2007. Theorising contingencies in management accounting research. In Chapman, C.S., Hopwood, A.G., Shields, M.D. (Eds.) Handbook of Management Accounting Research Elsevier, Oxford, pp. 163-206.

Chenhall, R.H., Morris, D. 1986. The impact of structure, environment, and interdependence on the perceived usefulness of management accounting systems. The Accounting Review 61, 16-35.

Chenhall R.H., Langfield-Smith, K., 2003. Performance Measurement and Reward Systems, Trust, and Strategic Change. Journal of Management Accounting Research 15, 117-143.

Crabtree, A.D., DeBusk, G.K., 2008. The Effects of Adopting the Balanced Scorecard on Shareholder Returns. Advances in Accounting, incorporating Advances in International Accounting 24 (1), 8-15.

De Geuser, F., Mooraj, S., Oyon, D., 2009. Does the balances scorecard add value? Empirical evidence on its effect on performance. European Accounting Review 18(1), 93-122.

Davis, S., Albright, T., 2004. An investigation of the effect of Balanced Scorecard implementation on financial performance. Management Accounting Research 15(2), 135-153.

Dean, J.W., Sharfman, M.P., 1996. Does decision process matter? A study of strategic decision making effectiveness. Academy of Management Journal 39(2), 368-396.

Dermer, J., 1990. The strategic agenda: Accounting for issues and support. Accounting, Organizations and Society 15 (1-2), 67-76.

Dess, G. G., Beard, D. W., 1984. Dimensions of organizational task environments. Administrative Science Quarterly 29, pp. 52-73.

Dillman, D.A., 2002. Mail and Internet surveys: the tailored design method. John Wiley \& Sons, New York.

Dutton, J., 1988. Understanding strategic agenda building and its implications for managing change. In: Pondy, L.R., Boland, R.J., Thomas, H., (Eds.) Managing ambiguity and change. John Wiley \& Sons, Chapter 7. 
Dutton, J.E., Ashford, S.J., 1993. Selling isues to top management. Academy of Management Review 18(3), 397-428.

Dutton, J.E., Duncan, R.B., 1987. The influence of the strategic planning process on strategic change. Strategic Management Journal 8, 103-116.

Dutton, J.M., Jackson, S.E. 1987. Categorizing strategic issues: links to organizational action. Academy of Management Review 12(1), 76-90.

Edwards, J. R., Lambert, L.S.L., 2007. Methods for integrating moderation and mediation: A general analytical framework using moderated path analysis. Psychological Methods 12, 1-22.

Fredrickson, J.W, Mitchell, T.R., 1984. Strategic Decision Processes: Comprehensiveness and Performance in an Industry with an Unstable Environment. Academy of Management Journal 27 (2), 399-423.

Garengo, P., Biazzo, S., Bititci, U.S., 2005. Performance measurement systems in SMEs: A review for a research agenda. International Journal of Management Reviews 7 (1), 25-47.

Gimbert, X., Bisbe, J., Mendoza, X., 2010. The Role of Performance Measurement Systems in Strategy Formulation Processes. Long Range Planning 43, 477-497.

Goll, I., Rasheed, A., 1997. Rational decision-making and firm performance: the moderating role of environment. Strategic Management Journal 18(7), 583-591.

Gordon, L., Narayanan, V., 1984. Management accounting systems, perceived environmental uncertainty and organizational structure: an empirical investigation. Accounting, Organizations and Society 9(1), 33-47.

Gul, F.A., Chia, Y.M., 1994. The effect of management accounting systems, perceived environmental uncertainty and decentralization on managerial performance: a test of three-way interaction. Accounting, Organizations and Society 19(4-5), 413-426.

Hall, M., 2008. The effect of comprehensive performance measurement systems on role clarity, psychological empowerment and managerial performance. Accounting, Organizations and Society 33(3), 141-163

Hall. M., 2011. Do comprehensive performance measurement systems help or hinder managers' mental model development? Management Accounting Research 22(2), 68-83.

Harrington, R.J., Lemak. D.J., Reed, R., Kendall, K.W., 2004. A question of fit: the links among environment, strategy formulation and performance. Journal of Business and Management 10(1), 15- 37.

Hartmann, F., 2005. The effects of tolerance for ambiguity and uncertainty on the appropriateness of accounting performance measures. Abacus 41, 241-264.

Hayes, A.F., 2009. Beyond Baron and Kenny: Statistical Mediation Analysis in the New Millennium. Communication Monographs 76(4), 408-420.

Henri, J-F., 2006. Management control systems and strategy: A resource-based perspective. Accounting, Organizations and Society 31, 529-558.

Hodgkinson, G.P, Whittington, R.W., Johnson, G., Schwarz, M., 2006. The role of strategy workshops in strategy development processes: formality, communication, coordination and inclusion. Long Range Planning 39, 479-496.

Hoque, Z., 2004. A contingency model of the association between strategy, environmental uncertainty and performance measurement: impact on organizational performance. International Business Review 13, $485-502$.

Hoque, Z., 2005. Linking environmental uncertainty to non-financial performance measures and performance: a research note. British Accounting Review 37, 471-481.

Hoque, Z., James, W., 2000. Linking balanced scorecard measures to size and market factors: impact on organizational performance. Journal of Management Accounting Research 12, 1-17.

Hough, J.R., White, M.A., 2003. Environmental dynamism and strategic decision-making rationality: an examination at the decision level. Strategic Management Journal 24, 481-489.

Ittner, C.D., Larcker, D.F., Randall, T., 2003. Performance implications of strategic performance measurement in financial services firms. Accounting, Organizations and Society 28, 715-741.

Johnson, G., Scholes, K., 2008. Exploring Corporate Strategy, 8th ed. Prentice Hall.

Kald, M., Nilsson, F., 2000. Performance measurement at Nordic companies. European Management Journal 18(1), 113-127.

Kaplan, R.S., Norton, D.P., 1996. The Balanced Scorecard. Harvard Business School Press, Boston.

Kaplan, R.S., Norton, D.P., 2000. The Strategy-Focused Organization, Harvard Business School Press, Boston.

Kaplan, R.S., Norton, D.P., 2004. Strategy Maps. Harvard Business School Press, Boston.

Kaplan, R.S., Norton, D.P., 2006. Alignment: Using the Balanced Scorecard to Create Corporate Synergies. Harvard Business School Press: Boston. 
Kaplan, R.S., Norton, D.P., 2008. Mastering the Management System. Harvard Business Review 86(1), 6377.

Kolehmainen, K., 2010. Dynamic strategic performance measurement systems: balancing empowerment and alignment. Long Range Planning 43, 527-554.

Langley, A., 1988. The roles of formal strategic planning. Long Range Planning 21(3), 40-50.

MacKinnon, D.P., Fairchild, A.J., Fritz, M.S., 2007 Mediation analysis. Annual Review of Psychology 58, 593-614.

MacKinnon, D.P., Lockwood, C.M., Hoffman, J.M., West, S.G., Sheets, V., 2002 A comparison of methods to test mediation and other intervening variable effects. Psychological Methods 7, 83-104.

Malina, M.A., Selto, F.H., 2001. Communicating and controlling strategy: an empirical study of the effectiveness of the balanced scorecard. Journal of Management Accounting Research 13, 47-90.

Markman, A. B., Gentner, D. 2001. Thinking, Annual Review of Psychology 52, 223-247.

Mathieu, J.E., Taylor, S.R., 2006. Clarifying conditions and decision points for mediational type inferences in Organizational Behavior. Journal of Organizational Behavior 27, 1031-1056.

Micheli, P., Manzoni, J-F., 2010. Strategic Performance Measurement Systems: Benefits, limitations and paradoxes. Long Range Planning 43(4), 465-476.

Miller, C.C., Cardinal, L.B., 1994. Strategic planning and firm performance: a synthesis of more than two decades of research. Academy of Management Journal 37, 1649-1665.

Miller, S., Wilson, D., Hickson, D., 2004. Beyond planning strategies for successfully implementing strategic decisions. Long Range Planning 37 (3), 201-218.

Miller, S., Hickson, D., Wison, D., 2008. From strategy to action: involvement and influence in top level decisions. Long Range Planning 41(6), 606-628.

Milliken, F.J., 1987. Three types of perceived uncertainty about the environment: State, effect, and response uncertainty. Academy of Management Review 12, 133-143.

Mintzberg, H., Quinn, J.B., Voyer, J., 1995. The strategy process. Prentice Hall, Englewood Cliffs, NJ.

Mintzberg, H., Waters, J., 1985. Of strategies, deliberate and emergent. Strategic Management Journal 6, $257-$ 272.

Murby, L., Gould, S. 2005. Effective performance management with the balanced scorecard. Technical Report CIMA / INSEAD.

Nadkarni, S., Barr, P., 2008. Environmental context, managerial cognition and strategic action: an integrated view. Strategic Management Journal 29, 1395-1427.

Neely, A., Adams, C., Kennerley, M., 2002. The Performance Prism: the scorecard for measuring and managing stakeholder relationships. Prentice Hall, London.

Neely, A., Gregory, M., Platts, K., 1995. Performance measurement system design: a literature review and research agenda. International Journal of Operations \& Production Management 15(4), 80-116.

Nørreklit, H., 2000. The balance on the balanced scorecard critical analysis of some of its assumptions. Management Accounting Research 11, 65-88.

Prahalad, C.K., Doz, Y.L., 1987. The multinational mission: balancing local demands and global vision. Free Press, New York.

Preacher, K.J., Hayes, A.F., 2004. SPSS and SAS procedures for estimating indirect effects in simple mediation models. Behavioral Research Methods 36, 717-731.

Preacher, K.J., Rucker, D.D., Hayes, A.F. 2007. Assessing moderated mediation hypotheses: Theory, method, and prescriptions. Multivariate Behavioral Research 42, 185-227.

Priem, R.L., Rasheed, A., Kotulic, A.G., 1995. Rationality in strategic decision processes, environmental dynamism and firm performance. Journal of Management 21(5), 913-929.

Rajagapolan, N.A., Rasheed, A., Datta, D.K., 1993. Strategic decision processes: critical review and future directions. Journal of Management 19, 349-384

Rigby, D., 2009. Management Tools. Bain and Company.

Schwenk, C.R., Schrader, C.B., 1993. Effects of formal strategic planning on financial performance in small firms: A meta-analysis. Entrepreneurship 17(3), 53-64.

Sharfman, M.P., Dean, J.W. 1991. Conceptualizing and Measuring the Organizational Environment: A Multidimensional Approach. Journal of Management 17 (4), 681-700.

Simerly, R., Li, M. 2000. Environmental dynamism, capital structure and performance: a theoretical integration and an empirical test. Strategic Management Journal 21, 31-49.

Simons, R., 1995. Levers of Control. Harvard Business School Press, Boston. 
Sinha, D.K., 1990. The contribution of formal planning to decisions. Strategic Management Journal 11, 479492.

Speckbacher, G., Bischof, J., Pfeiffer, T., 2003. A descriptive analysis on the implementation of balanced scorecards in German-speaking countries. Management Accounting Research 14, 361-387.

Tayler, W.B., 2010. The balanced scorecard as a strategy evaluation tool: The effects of implementation involvement and a causal-chain focus. The Accounting Review 85(3), 1095-1117.

Tuomela, T.S., 2005. The interplay of different levers of control: a case study of introducing a new performance measurement system. Management Accounting Research 16(3), 293-320.

Van der Stede, W., 2000. The relationship between two consequences of budgetary controls: budgetary slack creation and managerial short-term orientation. Accounting, Organizations and Society 25(6), 609-622.

Van der Stede, W., Young, S.M., Chen, C.X., 2005. Assessing the quality of evidence in empirical management accounting research: The case of survey studies. Accounting, Organizations and Society 30, 655-684.

Widener, S.K., 2006. Associations between strategic resource importance and performance measure use: The impact on firm performance. Management Accounting Research 17, 433-457.

Widener, S.K., 2007. An empirical analysis of the levers of control framework. Accounting, Organizations and Society 32(7-8), 757-788.

Wiersma, E., 2009. For which purposes do managers use Balanced Scorecards? Management Accounting Research 20(4), 239 - 251. 
Table 1. Sample by firm size, presence of SPMS and descriptive statistics

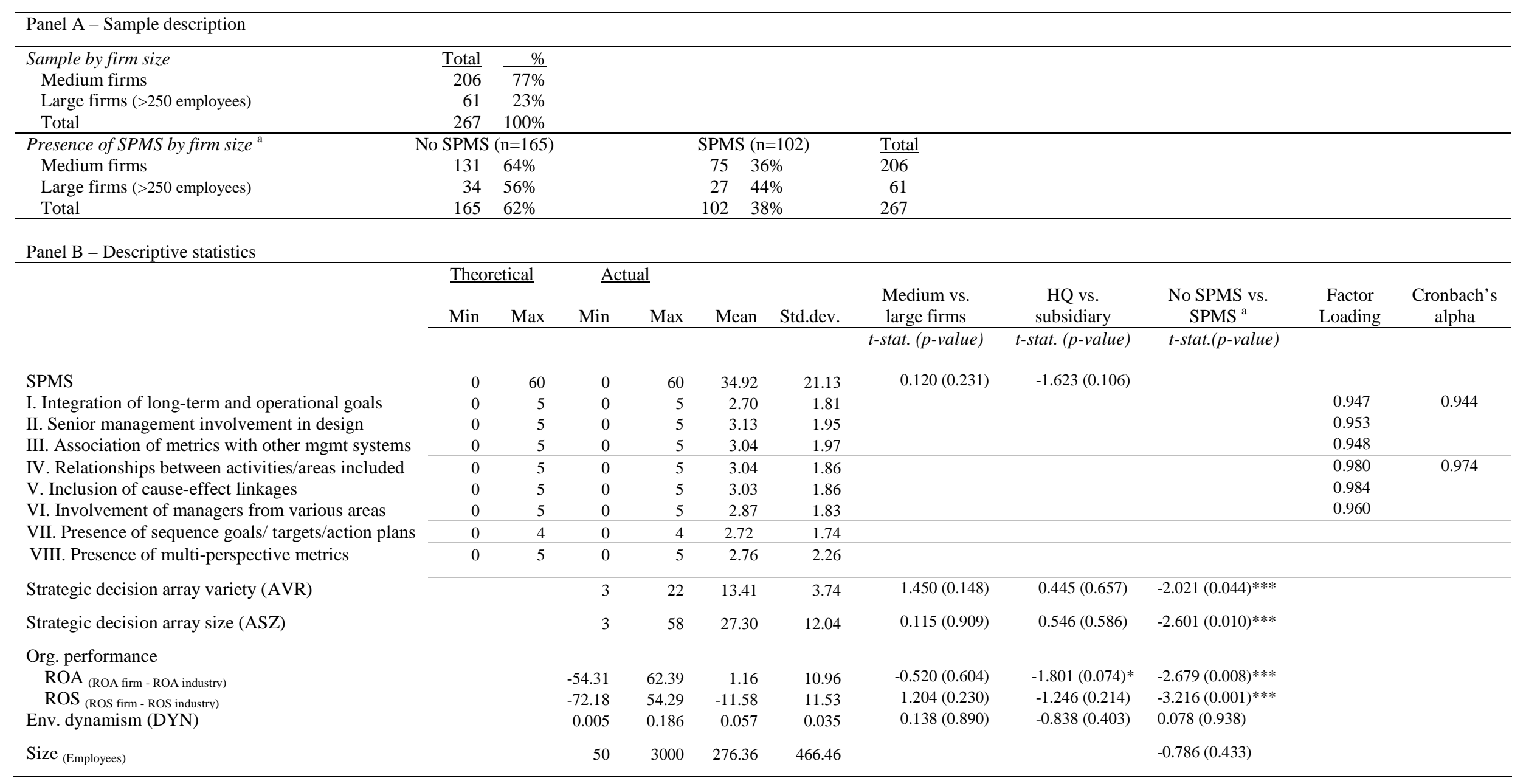

Note: $\mathrm{n}=267 ; * * * \mathrm{p}<.01 ; * * \mathrm{p}<.05 ; * \mathrm{p}<.10 .{ }^{a}$ We dichotomised SPMS in order to define their presence. SPMS were considered to be present in a firm if the scores of each of the four constitutive dimensions were higher than a predetermined threshold (specifically, at least two perspectives should be gathered and, for the remaining dimensions, scores should be in the upper third of the theoretical range) $(n=102)$. Otherwise, SPMS were considered not to be present $(n=165)$. 
To appear in Management Accounting Research

Table 2. Pearson correlation matrix

\begin{tabular}{|c|c|c|c|c|c|c|c|}
\hline & 1 & 2 & 3 & 4 & 5 & 6 & 7 \\
\hline \multicolumn{8}{|l|}{ 1. SPMS } \\
\hline 2. ASZ & $\begin{array}{r}.239 \\
(.000)\end{array}$ & & & & & & \\
\hline 3. AVR & $\begin{array}{r}.235 \\
(.000)\end{array}$ & $\begin{array}{r}.786 \\
(.000)\end{array}$ & & & & & \\
\hline 4. ROA & $\begin{array}{r}.096 \\
(.118)\end{array}$ & $\begin{array}{r}.134 \\
(.029)\end{array}$ & $\begin{array}{r}.009 \\
(.890)\end{array}$ & & & & \\
\hline 5. ROS & $\begin{array}{r}.165 \\
(.007)\end{array}$ & $\begin{array}{r}.194 \\
(.001)\end{array}$ & $\begin{array}{r}.157 \\
(.010)\end{array}$ & $\begin{array}{r}.656 \\
(.000)\end{array}$ & & & \\
\hline 6. DYN & $\begin{array}{r}.023 \\
(.712)\end{array}$ & $\begin{array}{r}-.090 \\
(.141)\end{array}$ & $\begin{array}{l}-.095 \\
(.122)\end{array}$ & $\begin{array}{r}.084 \\
(.172)\end{array}$ & $\begin{array}{r}.014 \\
(.826)\end{array}$ & & \\
\hline 7. SIZE & $\begin{array}{r}.106 \\
(.085)\end{array}$ & $\begin{array}{r}.062 \\
(.314)\end{array}$ & $\begin{array}{r}.122 \\
(.046)\end{array}$ & $\begin{array}{r}-.013 \\
(.830)\end{array}$ & $\begin{array}{r}.072 \\
(.240)\end{array}$ & $\begin{array}{c}-.052 \\
(.394)\end{array}$ & \\
\hline 8. HQ & $\begin{array}{r}.099 \\
(.106) \\
\end{array}$ & $\begin{array}{r}-.033 \\
(.586) \\
\end{array}$ & $\begin{array}{r}-.027 \\
(.657) \\
\end{array}$ & $\begin{array}{r}.124 \\
(.042) \\
\end{array}$ & $\begin{array}{r}.076 \\
(.214) \\
\end{array}$ & $\begin{array}{r}.049 \\
(.427) \\
\end{array}$ & $\begin{array}{r}.131 \\
(.033) \\
\end{array}$ \\
\hline
\end{tabular}

$\mathrm{n}=267$; -values in parentheses 
Table 3. Summary of results for mediation

\begin{tabular}{|c|c|c|c|c|c|c|c|c|c|}
\hline \multirow[b]{2}{*}{ Organisational performance $=$} & & \multicolumn{4}{|c|}{ Strategic decision array variety } & \multicolumn{4}{|c|}{ Strategic decision array size } \\
\hline & & (1) & ROA & (2) & ROS & (3) & $\mathrm{ROA}$ & (4) & ROS \\
\hline Panel A. Effects & $\begin{array}{l}\text { Predicted } \\
\text { sign }\end{array}$ & Coeff. & t-stat. & Coeff. & t-stat. & Coeff. & t-stat. & Coeff. & t-stat. \\
\hline $\begin{array}{l}\text { Organisational performance regressed } \\
\text { on SPMS }\end{array}$ & + & 0.130 & $(2.060)^{* *}$ & 0.185 & $(2.952)^{* * *}$ & 0.130 & $(2.060)^{* *}$ & 0.185 & $(2.952)^{* * *}$ \\
\hline $\begin{array}{l}\text { Strategic decision array regressed on } \\
\text { SPMS }\end{array}$ & + & 0.158 & $(2.508)^{* * *}$ & 0.158 & $(2.508)^{* * *}$ & 0.207 & $(3.309)^{* * *}$ & 0.207 & $(3.309)^{* * *}$ \\
\hline $\begin{array}{l}\text { Organisational performance regressed } \\
\text { on strategic decision array, controlling } \\
\text { for SPMS }\end{array}$ & + & -0.003 & $(-0.055)$ & 0.129 & $(2.113)^{* *}$ & 0.121 & $(1.956)^{* *}$ & 0.164 & $(2.695)^{* * *}$ \\
\hline $\begin{array}{l}\text { Organisational performance regressed } \\
\text { on SPMS, controlling for strategic } \\
\text { decision array }\end{array}$ & & 0.130 & $(2.041)^{* *}$ & 0.165 & $(2.614)^{* * *}$ & 0.105 & $(1.639)^{*}$ & 0.151 & $(2.388)^{* *}$ \\
\hline $\begin{array}{l}\text { Partial effect of control variable size on } \\
\text { organisational performance }\end{array}$ & & -0.039 & $(-0.637)$ & 0.034 & $(0.560)$ & -0.046 & $(-0.753)$ & 0.041 & $(0.674)$ \\
\hline $\begin{array}{l}\text { Partial effect of control variable } \\
\text { headquarter on organisational } \\
\text { performance }\end{array}$ & & 0.095 & $(1.502)$ & 0.032 & $(0.518)$ & 0.107 & $(1.696)^{*}$ & 0.037 & $(0.595)$ \\
\hline Panel B. Bootstrap (5000) results & & $\mathrm{M}$ & $\mathrm{SE}$ & $\mathrm{M}$ & SE & $\mathrm{M}$ & SE & $\mathrm{M}$ & $\mathrm{SE}$ \\
\hline Indirect Effect & & -0.000 & $(0.098)$ & $0.020 * *$ & $(0.011)$ & $0.025^{* *}$ & $(0.015)$ & $0.034 * *$ & $(0.016)$ \\
\hline $\begin{array}{l}\text { Panel C. Coefficient intervals } \\
\text { (confidence of } 95 \% \text { ) }\end{array}$ & & $\begin{array}{l}\text { Lower } \\
\text { limit }\end{array}$ & Upper limit & $\begin{array}{r}\text { Lower } \\
\text { limit }\end{array}$ & $\begin{array}{l}\text { Upper } \\
\text { Limit }\end{array}$ & $\begin{array}{l}\text { Lower } \\
\text { limit }\end{array}$ & Upper limit & $\begin{array}{r}\text { Lower } \\
\text { limit }\end{array}$ & $\begin{array}{l}\text { Upper } \\
\text { limit }\end{array}$ \\
\hline Indirect effect & & -0.020 & 0.021 & 0.004 & 0.052 & 0.005 & 0.073 & 0.009 & 0.075 \\
\hline
\end{tabular}

Note. $* * * \mathrm{p}<.01 ; * * \mathrm{p}<.05 ; * \mathrm{p}<.10$; One-tailed for the variable with predicted sign, two-tailed otherwise; $\mathrm{SE}=$ standard errors. Bootstrap sample size $=5,000$.

$\mathrm{n}=267$. The indirect effect hypothesized in $\mathrm{H} 1$ was also tested for the extended sample including recently appointed top managers ( $\mathrm{n}=294)$. Results are robust for this extended sample, with the exception of the indirect effect on ROA through array size, which lost significance when $\mathrm{n}=294$. 
Table 4. Regression results for conditional indirect effect of strategic decision arrays

\begin{tabular}{|c|c|c|c|c|c|c|c|c|c|}
\hline \multirow{2}{*}{$\begin{array}{l}\text { Panel A. } \\
\text { IV= Strat. decision array }\end{array}$} & \multirow{2}{*}{$\begin{array}{l}\text { Predicted } \\
\text { sign }\end{array}$} & \multicolumn{4}{|c|}{ Strategic decision array variety } & \multicolumn{4}{|c|}{ Strategic decision array size } \\
\hline & & Coeff. & (t-stat.) & & & Coeff. & (t-stat.) & & \\
\hline SPMS & & 0.157 & $(2.513) * *$ & & & 0.207 & $(3.316)^{* * * *}$ & & \\
\hline Env. dynamism (DYN) & & -0.079 & $(-1.306)$ & & & -0.081 & $(-1.324)$ & & \\
\hline SPMS x DYN & + & -0.066 & $(-1.088)$ & & & -0.053 & $(-0.872)$ & & \\
\hline SIZE & & 0.113 & $(1.853)^{*}$ & & & 0.048 & $(0.793)$ & & \\
\hline $\mathrm{HQ}$ & & -0.078 & $(-1.237)$ & & & -0.089 & $(-1.414)$ & & \\
\hline \multirow[t]{2}{*}{ Panel B. IV = performance } & \multirow{2}{*}{$\begin{array}{l}\text { Predicted } \\
\text { sign }\end{array}$} & (1) ROA & & (2)ROS & & (3) ROA & & (4) ROS & \\
\hline & & Coeff. & (t-stat.) & Coeff. & (t-stat.) & Coeff. & (t-stat.) & Coeff. & (t-stat.) \\
\hline SPMS & & 0.124 & $(1.923) *$ & 0.149 & $(2.368)^{* * *}$ & 0.096 & $(1.504)$ & 0.137 & $(2.169)^{* *}$ \\
\hline Env. dynamism (DYN) & & 0.063 & $(1.003)$ & 0.002 & $(0.026)$ & 0.071 & $(1.151)$ & 0.005 & $(0.085)$ \\
\hline SPMS x DYN & & 0.051 & $(0.820)$ & 0.025 & $(0.403)$ & 0.066 & (1.063) & 0.042 & $(0.686)$ \\
\hline Array variety (AVR) & & 0.014 & $(0.223)$ & 0.154 & $(2.485)^{* * *}$ & - & - & - & - \\
\hline AVR x DYN & - & -0.049 & $(-0.799)$ & -0.143 & $(-2.374) * * *$ & - & - & - & - \\
\hline Array size (ASZ) & & - & - & - & - & 0.135 & $(2.169)^{* * *}$ & 0.175 & $(2.863)^{* * * *}$ \\
\hline ASZ x DYN & - & - & - & - & - & -0.071 & $(-1.142)$ & -0.160 & $(-2.614) * * *$ \\
\hline SIZE & & -0.040 & $(-0.649)$ & 0.028 & $(0.451)$ & -0.041 & $(-0.677)$ & 0.046 & $(0.771)$ \\
\hline $\mathrm{HQ}$ & & 0.094 & $(1.482)$ & 0.039 & $(0.636)$ & 0.106 & $(1.681)^{*}$ & 0.043 & $(0.702)$ \\
\hline \multicolumn{10}{|c|}{ Panel C. Conditional indirect effect at environmental dynamism $=$ Mean \pm 1 SD } \\
\hline Env.dynamism & & $\begin{array}{r}\text { Boot indirect } \\
\text { effect }\end{array}$ & (z-stat) & $\begin{array}{r}\text { Boot indirect } \\
\text { effect }\end{array}$ & (z-stat) & $\begin{array}{r}\text { Boot indirect } \\
\text { effect }\end{array}$ & (z-stat) & $\begin{array}{r}\text { Boot indirect } \\
\text { effect }\end{array}$ & (z-stat) \\
\hline$-1 \mathrm{Sd}(0.022)$ & & 0.014 & $(0.549)$ & 0.067 & $(1.999) * *$ & 0.054 & $(1.700)^{*}$ & 0.087 & $(2.313)^{* *}$ \\
\hline Mean (0.057) & & 0.002 & $(0.208)$ & 0.024 & $(1.833) *$ & 0.028 & (1.699)* & 0.036 & $(2.236)^{* *}$ \\
\hline$+1 \mathrm{Sd}(0.092)$ & & -0.003 & $(-0.385)$ & 0.001 & $(-0.0433)$ & 0.009 & $(0.604)$ & 0.002 & $(0.157)$ \\
\hline \multicolumn{10}{|c|}{ Panel D. Conditional indirect effect at range of values of environmental dynamism } \\
\hline Env. Dynamism & & $\begin{array}{r}\text { Boot indirect } \\
\text { effect }\end{array}$ & (z-stat) & $\begin{array}{r}\text { Boot indirect } \\
\text { effect }\end{array}$ & (z-stat) & $\begin{array}{r}\text { Boot indirect } \\
\text { effect }\end{array}$ & (z-stat) & $\begin{array}{r}\text { Boot indirect } \\
\text { effect }\end{array}$ & (z-stat) \\
\hline 0.005 & & 0.023 & $(0.596)$ & 0.095 & $(1.880) *$ & 0.069 & (1.574) & 0.119 & $(2.082)^{* *}$ \\
\hline 0.014 & & 0.018 & $(0.576)$ & 0.079 & $(1.945) *$ & 0.061 & (1.641) & 0.102 & $(2.202)^{* *}$ \\
\hline 0.023 & & 0.014 & $(0.546)$ & 0.065 & $(2.005)^{* * *}$ & 0.053 & $(1.705)^{*}$ & 0.086 & $(2.323) * *$ \\
\hline 0.032 & & 0.010 & $(0.499)$ & 0.053 & $(2.045)^{* * *}$ & 0.046 & $(1.759)^{*}$ & 0.071 & $(2.425)^{* *}$ \\
\hline 0.041 & & 0.007 & $(0.428)$ & 0.041 & $(2.043)^{* * *}$ & 0.038 & $(1.785)^{*}$ & 0.057 & $(2.469)^{* * *}$ \\
\hline 0.050 & & 0.004 & $(0.384)$ & 0.031 & $(1.964)^{* * *}$ & 0.032 & $(1.762)^{*}$ & 0.045 & $(2.398)^{* * *}$ \\
\hline 0.059 & & 0.002 & $(0.159)$ & 0.022 & $(1.766) *$ & 0.026 & $(1.664)^{*}$ & 0.033 & $(2.153)^{* *}$ \\
\hline 0.068 & & -0.000 & $(-0.041)$ & 0.014 & (1.417) & 0.021 & (1.474) & 0.023 & $(1.719)^{*}$ \\
\hline 0.077 & & -0.002 & $(-0.236)$ & 0.008 & $(0.904)$ & 0.016 & (1.201) & 0.014 & (1.138) \\
\hline 0.087 & & -0.003 & $(-0.358)$ & 0.003 & $(0.269)$ & 0.012 & $(0.876)$ & 0.006 & $(0.486)$ \\
\hline 0.096 & & -0.003 & $(-0.389)$ & -0.005 & $(-0.235)$ & 0.008 & $(0.545)$ & -0.007 & $(-0.093)$ \\
\hline
\end{tabular}

Note: Bootstrap sample size $=5,000 . * * * \mathrm{p}<.01 ; * * \mathrm{p}<.05 ; * \mathrm{p}<.10 ;$ One-tailed for the variables with predicted sign, two-tailed otherwise.

$\mathrm{n}=267$. Moderations and mediated moderations hypothesised in $\mathrm{H} 2, \mathrm{H} 3$, and H4, were also tested for the extended sample including recently appointed top managers ( $\mathrm{n}=294)$. Results are in general robust for this extended sample, with the exceptions of an increase in the level of significance of ASZ*DYN on ROA ( <.10 if $n=294)$ and a decrease in the level of significance of the indirect effects, which are significant $(\mathrm{p}>.05$ or $\mathrm{p}>.10)$ only at values below the mean of environmental dynamism when $\mathrm{n}=294$. 
Figure 1. General theoretical model

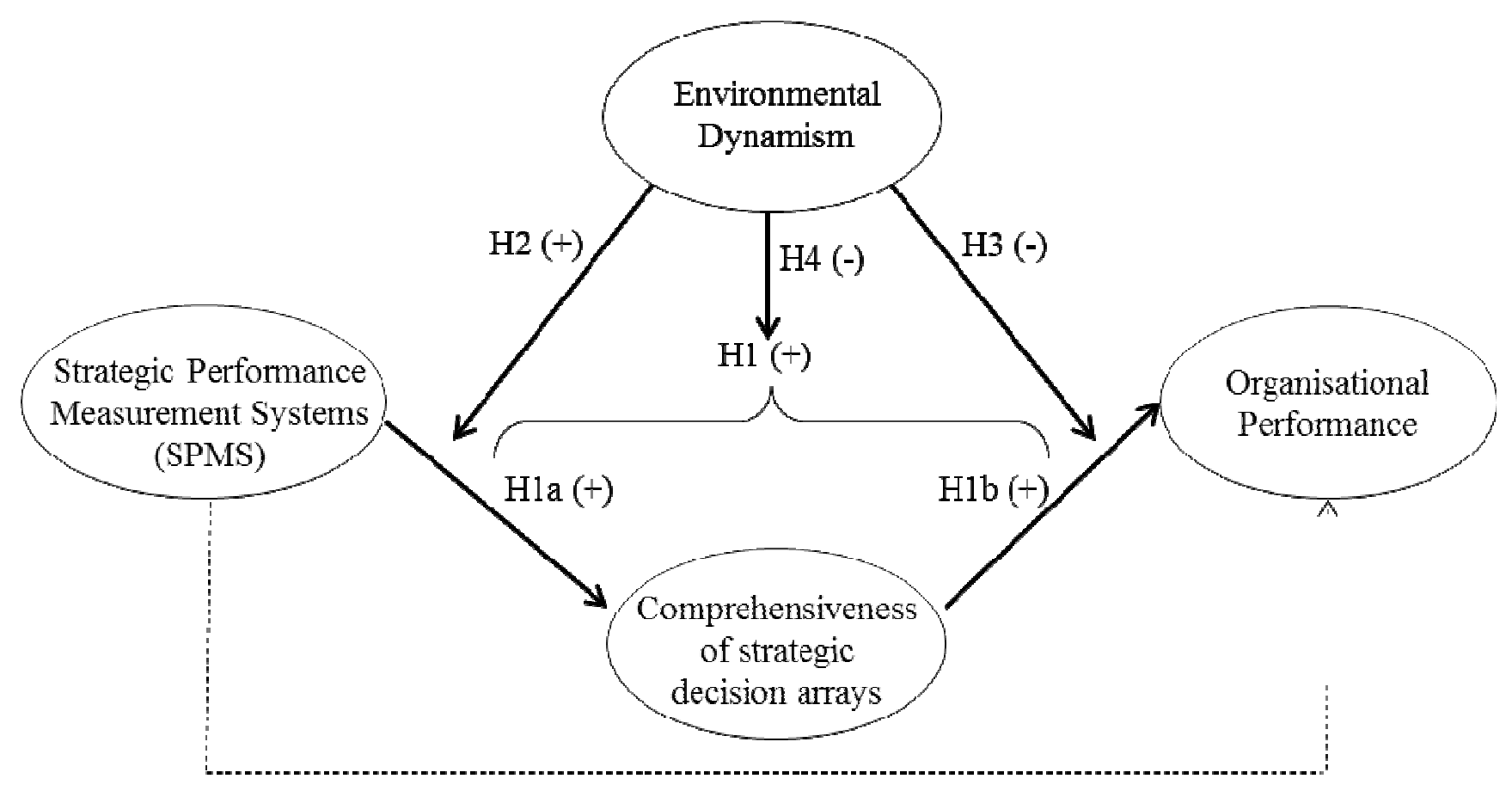

